\title{
A Case Study of the Impediments to the Commercialization of Research at the University of Kentucky [version 1; peer
}

\section{review: 3 approved with reservations]}

\author{
Nathan L. Vanderford (D1), Elizabeth Marcinkowski² \\ ${ }^{1}$ Markey Cancer Center and Department of Toxicology and Cancer Biology, College of Medicine, University of Kentucky, Lexington, \\ Kentucky, 40506, USA \\ ${ }^{2}$ Agricultural Biotechnology Program, College of Agriculture, Food and Environment, University of Kentucky, Lexington, Kentucky, \\ 40506, USA
}

V1 First published: 28 May 2015, 4:133
https://doi.org/10.12688/f1000research.6487.1

Latest published: 04 Aug 2015, 4:133

https://doi.org/10.12688/f1000research.6487.2

\begin{abstract}
The commercialization of university-based research occurs to varying degrees between academic institutions. Previous studies have found that multiple barriers can impede the effectiveness and efficiency by which academic research is commercialized. This case study was designed to analyze the status of the commercialization activity at the University of Kentucky via a survey and interview with a successful academic entrepreneur in order to determine the impediments the individual perceived during the commercialization process. The study also garnered insight from the individual as to how the commercialization process could be improved. Issues with infrastructure were highlighted as the most significant barrier faced by the individual. The research subject also suggested that commercialization activity may generally increase if a number of factors were mitigated. Such insight can be communicated to the administrative leadership of the commercialization process at the University of Kentucky. Long term, improving university-based research commercialization will allow academic researchers to be more active and successful entrepreneurs such that intellectual property will progress more freely to the marketplace for the benefit of inventors, universities, and society.
\end{abstract}

Keywords

Research commercialization, entrepreneurship, intellectual property, technology transfer, disclosures, patents, license, start-ups

\section{Open Peer Review \\ Approval Status ? \\ $1 \quad 2 \quad 3$ \\ version 2 \\ (revision) \\ 04 Aug 2015 \\ version 1 \\ 28 May 2015

$?$
view
$?$
view

$\checkmark$
view
$?$
view

$\checkmark$
view
$?$
view \\ 1. Jessica Silvaggi, UWM Research Foundation, Milwaukee, USA \\ 2. Scott Crick, Washington University, St Louis, USA \\ 3. Evan Facher, University of Pittsburgh, \\ Pittsburgh, USA \\ Any reports and responses or comments on the article can be found at the end of the article.}


Corresponding author: Nathan L. Vanderford (nathan.vanderford@uky.edu)

Competing interests: The authors have no competing interests.

Grant information: The author(s) declared that no grants were involved in supporting this work.

Copyright: (c) 2015 Vanderford NL and Marcinkowski E. This is an open access article distributed under the terms of the Creative Commons Attribution License, which permits unrestricted use, distribution, and reproduction in any medium, provided the original work is properly cited. Data associated with the article are available under the terms of the Creative Commons Zero "No rights reserved" data waiver (CCO 1.0 Public domain dedication).

How to cite this article: Vanderford NL and Marcinkowski E. A Case Study of the Impediments to the Commercialization of Research at the University of Kentucky [version 1; peer review: 3 approved with reservations] F1000Research 2015, 4:133 https://doi.org/10.12688/f1000research.6487.1

First published: 28 May 2015, 4:133 https://doi.org/10.12688/f1000research.6487.1 


\section{Introduction}

Research is a vital component of the mission of universities, and indeed academic institutions conduct a substantial volume of research that is funded by government, industry and philanthropic agencies. Development or the commercialization of research should also be a key component of the research mission such that novel ideas, techniques and products can enter the marketplace for the consumption and benefit of society. In order to facilitate academic-based commercialization, legislation, such as the Bayh-Dole Act, provides universities the legal framework for commercializing the research that is developed within university settings ${ }^{1,2}$.

In a commercialization survey conducted by the Association of University Technology Managers (AUTM), in 2013, United Statesbased institutions obtained over 5,000 new patents, executed over 5,000 licensing agreements, formed over 800 start-up companies and generated $\$ 2.75$ billion in license income ${ }^{3}$. Despite this overall success, academic researchers experience many issues that obstruct the commercialization of research within higher education settings. Previous studies at academic institutions have documented the challenges to the commercialization process that include, but are not limited to: risk aversion; constraints on faculty time; lack of financial support; policy/regulation barriers; infrastructure insufficiencies; lack of a common understanding of the value of research commercialization; lack of entrepreneurial thinking among faculty; and lack of interaction and collaboration between universities and industry $^{4-10}$. A previous study at the University of Kentucky found that expense, time constraints, insufficient infrastructure and lack of industry partnerships were the most common factors experienced by cancer researchers that impede research commercialization ${ }^{11}$. Ultimately, challenges to the effective and efficient commercialization of research inhibits obtaining the maximum benefit of university research in that such barriers can prevent university-based innovation from progressing to the marketplace for the benefit of inventors, universities and society.

The University of Kentucky commercializes its research through the Intellectual Property Development and Technology Transfer Office, a unit of the Office of the Vice President for Research. Through this office, the university's research commercialization activities are historically modest compared to its benchmark institutions. The university currently ranks last among its benchmark institutions in regard to several commercialization metrics including in staffing, invention disclosures, patent applications and license/options executed (Table 1). And, growth in commercialization activity has been relatively flat from 2010-2013 with the exception of a recent increase in license income (Table 2). These data could suggest that the University of Kentucky may experience additional commercialization barriers as compared to its benchmark institutions and/or a higher magnitude of common barriers among institutions.

Table 1. University of Kentucky research commercialization metrics versus select benchmark institutions $(2013)^{\star}$.

\begin{tabular}{|c|c|c|c|c|c|c|c|}
\hline $\begin{array}{l}\text { Name of } \\
\text { Institution }\end{array}$ & $\begin{array}{l}\text { Licensing } \\
\text { FTE }\end{array}$ & $\begin{array}{c}\text { Invention } \\
\text { Disclosures }\end{array}$ & $\begin{array}{c}\text { Patent } \\
\text { Applications }\end{array}$ & $\begin{array}{l}\text { Patents } \\
\text { Issued }\end{array}$ & $\begin{array}{l}\text { Licenses } \\
\text { and } \\
\text { Options } \\
\text { Executed }\end{array}$ & Start-ups & $\begin{array}{l}\text { License } \\
\text { Income } \\
\text { Received }\end{array}$ \\
\hline $\begin{array}{l}\text { Michigan State } \\
\text { University }\end{array}$ & 5.50 & 122 & 49 & 46 & 33 & 1 & $\$ 3,302,322$ \\
\hline $\begin{array}{l}\text { Ohio State } \\
\text { University }\end{array}$ & 9.00 & 384 & 155 & 62 & 50 & 10 & $\$ 2,105,127$ \\
\hline $\begin{array}{l}\text { University of } \\
\text { Arizona }\end{array}$ & 8.50 & 144 & 76 & 27 & 48 & 3 & $\$ 926,023$ \\
\hline $\begin{array}{l}\text { University of } \\
\text { Florida }\end{array}$ & 13.50 & 335 & 152 & 107 & 140 & 16 & $\$ 28,067,988$ \\
\hline $\begin{array}{l}\text { University of } \\
\text { lowa }\end{array}$ & 6.00 & 96 & 53 & 24 & 29 & 6 & $\$ 1,205,342$ \\
\hline $\begin{array}{l}\text { University of } \\
\text { Kentucky }\end{array}$ & 2.00 & 58 & 17 & 30 & 9 & 3 & $\$ 4,800,000$ \\
\hline $\begin{array}{l}\text { University of } \\
\text { Michigan }\end{array}$ & 9.00 & 412 & 148 & 128 & 108 & 9 & $\$ 14,464,565$ \\
\hline $\begin{array}{l}\text { University of } \\
\text { Minnesota }\end{array}$ & 18.00 & 331 & 148 & 64 & 91 & 14 & $\$ 38,030,470$ \\
\hline $\begin{array}{l}\text { University of } \\
\text { North Carolina, } \\
\text { Chapel Hill }\end{array}$ & 6.00 & 138 & 72 & 25 & 56 & 14 & $\$ 3,783,545$ \\
\hline $\begin{array}{l}\text { University of } \\
\text { Wisconsin- } \\
\text { Madison }\end{array}$ & 18.00 & 386 & 167 & 157 & 63 & 7 & $\$ 94,170,000$ \\
\hline
\end{tabular}

*Data obtained from the fiscal year 2013 AUTM report. 


\section{Table 2. University of Kentucky research commercialization activity,} 2010-2013*.

\begin{tabular}{|l|c|c|c|c|}
\hline $\begin{array}{l}\text { Commercialization } \\
\text { Activity }\end{array}$ & $\mathbf{2 0 1 0}$ & $\mathbf{2 0 1 1}$ & $\mathbf{2 0 1 2}$ & $\mathbf{2 0 1 3}$ \\
\hline Disclosures & 57 & 59 & 83 & 58 \\
\hline Patent Applications & 28 & 22 & 12 & 17 \\
\hline Patents Issued & 28 & 26 & 29 & 30 \\
\hline Licenses/Options & 9 & 8 & 9 & 9 \\
\hline Executed & 6 & 7 & 6 & 3 \\
\hline Start-ups & $\$ 2,161,743$ & $\$ 1,544,664$ & $\$ 1,628,264$ & $\$ 4,800,000$ \\
\hline License Income & & &
\end{tabular}

*Data obtained from the fiscal year 2010-2013 AUTM reports.

The study herein focused on understanding the impediments to commercializing research at the University of Kentucky from the perspective of a single faculty member that has been successful in the continuum of commercialization through successfully obtaining multiple patents, licensing intellectual property and forming multiple start-up companies. The rationale for conducting the study with one successful academic entrepreneur was that we believed that such a serial entrepreneur could provide more insight into the commercialization process versus someone that had more limited or no experience in commercializing research.

\section{Methods}

The study herein is modeled closely after a similar, larger scale study conducted at the University of Kentucky specifically among cancer researchers ${ }^{11}$. The methodology and design of this study was qualitative in nature and was based on two modules: an online survey (included as Supplementary materials S1) followed by a face-to-face interview. The selection criteria for inclusion in the study was that the selected participant must be a faculty member, have an active research program and be a successful academic entrepreneur based on having obtained patents, licensed intellectual property and created start-up companies. The research subject for this study was identified through searches of publically available databases containing information on the selection criteria. For module one, data were collected and managed using the Research Electronic Data Capture (REDCap) tool. REDCap is a secure, Internet-based study-support application $^{12}$. Module two data were recorded in written format during the face-to-face interview.

This study was determined to not require review by the University of Kentucky Institutional Review Board. The research subject consented to participate in the study electronically via engagement with the online survey and chose to participate in both modules of the study. The participant chose to remain anonymous beyond interaction with the investigators involved in the study.

\section{Results \\ Professional productivity and commercialization perspective}

The first series of questions aimed to assess the subject's category of research, professional productivity and the perspective he has on research commercialization. The subject classified his research as "translational;" he felt satisfied with his level of professional productivity in terms of publishing research manuscripts, obtaining grant funding and other means of academic productivity; and he indicated that he intends to commercialize additional research in the future. Despite believing that research commercialization is important in the academic setting and that his research field values such work, he feels that the University of Kentucky places little emphasis on and thus does not greatly value research commercialization (Table 3).

\section{Impediments to research commercialization}

The second set of questions addressed the research subject's perceived impediments to commercializing research. The subject responded that risk, lack of investors, commercialization infrastructure, unsupportive university and federal policies, and "other barriers not listed" prohibited his efforts to effectively and efficiently commercialize research (Table 4). In the face-to-face interview, the subject indicated that the "other barriers" included major prohibiting factors such as the lack of university support in areas of market analysis, grant development, and navigating legal matters including conflict of interest and intellectual property ownership issues. Of these "other" items, we had anticipated that such factors could be captured under the commercialization infrastructure and/or policy categories of answer choices in the survey. Ultimately, the subject indicated that infrastructure issues are the most significant factors that impede research commercialization at the University of Kentucky. The subject also discussed how some of these barriers are more challenging and more difficult to overcome and that he felt that the barriers he has encountered are different at other 
Table 3. Professional productivity and commercialization perspective.

\begin{tabular}{|c|c|}
\hline Question & Answer \\
\hline Which category best describes your research? & Translational \\
\hline $\begin{array}{l}\text { Do you feel that your research results are sufficiently utilized } \\
\text { through the generation of publications, grants, and other forms of } \\
\text { professional productivity? }\end{array}$ & Yes \\
\hline Do you intend to commercialize your research in the future? & Yes \\
\hline $\begin{array}{l}\text { Do you think research commercialization is important to promote } \\
\text { within an academic setting? }\end{array}$ & Yes \\
\hline $\begin{array}{l}\text { Do you think the University of Kentucky places an emphasis on } \\
\text { academic research commercialization to faculty? }\end{array}$ & No \\
\hline $\begin{array}{l}\text { Do you think your research field places an emphasis on academic } \\
\text { research commercialization? }\end{array}$ & Yes \\
\hline
\end{tabular}

Table 4. Impediments to research commercialization.

\begin{tabular}{|l|c|}
\hline \multicolumn{1}{|c|}{ Potential Barrier } & Answer \\
\hline $\begin{array}{l}\text { There are no barriers to commercializing research at the } \\
\text { University of Kentucky }\end{array}$ & No \\
\hline There is unwanted risk associated with commercialization & Yes \\
\hline I lack the expendable time & No \\
\hline There is excessive expense & No \\
\hline There is a lack of investors & Yes \\
\hline $\begin{array}{l}\text { There is a lack of infrastructure including facilities and staff to } \\
\text { help in the commercialization process }\end{array}$ & Yes \\
\hline Unsupportive University policies, procedures and/or regulations & Yes \\
\hline Unsupportive federal policies, procedures and/or regulations & Yes \\
\hline There is a lack of industry partners & No \\
\hline Limited or no commercial application of my research exists & No \\
\hline There is a lack of importance to academia & No \\
\hline There is a lack of importance to my field & No \\
\hline There is a lack of benefit to society & No \\
\hline I have no interest in commercialization & No \\
\hline Other barriers not listed & Yes \\
\hline
\end{tabular}

universities. Thus, similar to the previous study among cancer researchers ${ }^{11}$, these data suggest that this faculty member experiences multiple barriers in the commercialization process. Additionally, in comparison with previous studies ${ }^{4-11}$, the data may suggest that not all barriers are consistent or common between individual faculty members (for example, expense, time constraints, insufficient infrastructure, and lack of industry partnerships were the most common barriers experienced among University of Kentucky cancer researchers ${ }^{11}$ ).

Factors that could enhance research commercialization The final set of questions were meant to determine which impediments would need to be overcome in order to increase faculty participation in research commercialization. Interestingly, the subject indicated that the barriers in the commercialization process do not deter him from attempting to commercialize his research, however, he believed that reducing/mitigating all the potential barriers surveyed, other than addressing royalty pay to inventors, would enhance research commercialization activity at the University of Kentucky (Table 5). The subject also indicated that he would utilize outside (off campus) commercialization resources to lower the barriers he faces in order to improve his commercialization efforts. These data are similar to the feelings reported by cancer researchers ${ }^{11}$ in which respondents believed that a greater number of mitigating factors compared to the identified barriers in the previous set of questions would presumably increase commercialization activity. 
Table 5. Factors that could enhance research commercialization.

\begin{tabular}{|l|c|}
\hline \multicolumn{1}{|c|}{ Factor } & Answer \\
\hline Offering protected time specifically for commercialization activities & Yes \\
\hline Increasing information on how to commercialize & Yes \\
\hline Increasing financial support & Yes \\
\hline $\begin{array}{l}\text { Better and/or more infrastructure including facilities and staff to } \\
\text { help in the commercialization process }\end{array}$ & Yes \\
\hline Revising university policies, procedures and/or regulations & Yes \\
\hline Revising federal policies, procedures and/or regulations & Yes \\
\hline Increasing links to industry & Yes \\
\hline $\begin{array}{l}\text { Increasing emphasis placed by academia and/or my research } \\
\text { field on the importance of research commercialization }\end{array}$ & Yes \\
\hline Greater personal benefits including more royalty pay & No \\
\hline Greater societal benefits & Yes \\
\hline Nothing would help & No \\
\hline
\end{tabular}

\section{Conclusion}

This case study investigated the mindset of one successful academic entrepreneur at the University of Kentucky in relation to research commercialization and in context with the university's general commercialization activity. The general status of the institution's commercialization activity is modest relative to its benchmark institutions and stagnant in growth over time. The research subject identified several factors that generally impede research commercialization and that mitigating many factors may increase commercialization activity. Infrastructure was pinpointed as the major issue impeding research commercialization at the university. While generally fitting with the impediments found at other universities and among cancer researchers at the University of Kentucky ${ }^{4-11}$, the results suggest that not all barriers are common or consistent between faculty and that some impediments may be more prohibitive than others.

These data can be shared with the University of Kentucky's Intellectual Property Development and Technology Transfer Office and the Office of the Vice President for Research and used as a guide to make changes that will improve the research commercialization process. The research subject's comments regarding commercialization infrastructure may be particularly important to address in order to enhance commercialization activity at the university.
Additionally, similar work could be conducted at and among other institutions. For example, a survey similar to the one herein and that used in the prior study ${ }^{11}$ could be incorporated into the yearly AUTM licensing survey in order to gauge, on a much broader scale, the impediments to academic research commercialization as well as to understand how other institutions are mitigating such impediments. Understanding how institutions that are highly successful in commercializing research mitigate barriers in the process would be greatly beneficial to institutions that have low to modest commercialization activity.

Author contributions

NLV and EM conceived and designed the study; conducted the study; analyzed the data; and wrote the paper. This research project was completed, in part, to fulfill the requirements of EM's Bachelor of Science degree in Agricultural Biotechnology.

\section{Competing interests}

The authors have no competing interests.

\section{Grant information}

The author(s) declared that no grants were involved in supporting this work.

\section{Supplementary materials}

\section{Supplementary materials S1.} Research Commercialization Survey

Click here to access the data. 
1. Loise V, Stevens AJ: The Bayh-Dole Act turns 30. Sci Transl Med. 2010; 2(52): $52 \mathrm{~cm} 27$.

PubMed Abstract | Publisher Full Text

2. Thursby JG, Thursby MC: Intellectual property. University licensing and the Bayh-Dole Act. Science. 2003; 301(5636): 1052. PubMed Abstract | Publisher Full Text

3. Association of University Technology Managers. AUTM U.S. Licensing Activity Survey: FY2013. Deerfield, IL: Hippenmeyer P, Hawkins S, Mroz MA, Robertson R, Ruey N, and Stevens AJ. 2015. Reference Source

4. Atlantic Canada Opportunities Agency. University Research Activity Private Sector Collaboration and Commercialization of Research in an Academic Environment: Memorial University of Newfoundland as a Case Study. New Brunswick, Canada: Locke W, Lynch S, Girard B. 2002. Reference Source

5. ERA-Net NEURON. Transferring Technology from Bench to Bedside: Practices, Barriers, Policies. Bonn, Germany: Meyer M, Glod F. 2011. Reference Source

6. Klein R, Haan UD, Goldberg Al: Overcoming Obstacles Encountered on the way to Commercialize University IP. Journal of Technology Transfer. 2010; 35(6): 671-679.

Publisher Full Text
7. Lawson C: Academic Patenting: The Importance of Industry Support. J Technol Transf. 2013; 38(4): 509-535.

Publisher Full Text

8. O'Shea RP, Allen TJ, Chevalier A, et al:: Entrepreneurial orientation, technology transfer and spinoff performance of U.S. universities. Research Policy. 2005; 34(7): 994-1009.

Publisher Full Text

9. Powers JB, Campbell EG: Technology Commercialization Effects on the Conduct of Research in Higher Education. Res High Educ. 2011; 52(3): 245-260. PubMed Abstract | Publisher Full Text | Free Full Text

10. Swedish Institute for Growth Policy Studies. Commercialization of Life-Science Research at Universities in the United States, Japan and China. Ostersund, Sweden: Nilsson AS. 2006.

Reference Source

11. Vanderford NL, Weiss LT, Weiss HL: A survey of the barriers associated with academic-based cancer research commercialization. PLoS One. 2013; 8(8): e72268. PubMed Abstract | Publisher Full Text | Free Full Text

12. Harris PA, Taylor R, Thielke R, et al.: Research electronic data capture (REDCap)--a metadata-driven methodology and workflow process for providing translational research informatics support. J Biomed Inform. 2009; 42(2): 377-381.

PubMed Abstract | Publisher Full Text | Free Full Text 


\section{Open Peer Review}

\section{Current Peer Review Status: ? ? ?}

Version 1

Reviewer Report 01 July 2015

https://doi.org/10.5256/f1000research.6961.r9270

(c) 2015 Facher E. This is an open access peer review report distributed under the terms of the Creative Commons Attribution License, which permits unrestricted use, distribution, and reproduction in any medium, provided the original work is properly cited.

\section{Evan Facher \\ Enterprise Development, University of Pittsburgh, Pittsburgh, PA, USA}

The study by Vanderford and Marcinkowski attempts to identify challenges to the commercialization of innovations discovered at their institute of higher learning, the University of Kentucky. The goal of this work is to improve the sluggish local climate for translation of discoveries by communicating the findings resulting from this effort back to administrative leadership with the hope that the identification of these impediments leads to real change. By deploying a survey and subsequent interviews the authors plan to generate learnings sufficient to form the basis of their recommendations.

Movement of research discoveries from academic institutes to the marketplace is important not only for these discoveries to have their societal impact but also to drive economic growth of a region. The juxtaposition of most new jobs created over the last two decades coming from startup companies and much innovation from academia serving as the impetus for these new entities hints at the regional criticality of a university being able to successfully translate its discoveries into products reaching the market.

While the Vanderford and Marcinkowski article has a solid thesis and very good intent, it is however limited (in this reviewers mind) by a handful of items. First, the conclusions the authors generate are based on the survey and interview of a single academic entrepreneur. The data achieved from this individual is certainly very valuable but it might not be reflective of the other individuals on campus that have had experiences with commercialization of university-based research. The challenges described by this individual on campus ring true of the commercialization issues found throughout other academic organizations; however due to the small sample size it is hard to draw solid conclusions for the University of Kentucky as a whole. As one of the aims of the study is to report findings back to the administration with the goal of impacting change, I would suggest that the senior leadership, while sympathetic to the challenges expressed by the authors, will not institute changes based on such a small set of data that may not accurately reflect the general experiences of its academic entrepreneurs in totality.

I would recommend that the authors attempt to increase the number of study subjects to enhance 
the power of their research. In addition to surveys/interviews with academics that have successfully commercialized their innovations on campus, I would strongly urge the authors to include a set of individuals that have had unsuccessful experiences as well. Learnings from this cohort might provide an additional set of data to further drive the goals of enhancing translation at their institute.

The second item I would suggest the authors to contemplate in their assessments is expanding their perspectives on reasons for an innovation not being commercialized. It seems as if the main focus of the surveys/interviews is on structural elements involved in the workflow for moving a university idea to commercialization. It is often that the main reason for the lack of translation has nothing to do with the internal processes for moving the opportunity forward but rather that the innovation never really addressed a true market need despite the solid academic research. As such, regardless of the view of commercialization risk, the number of investors, the supportiveness of university policies or facilities/staff to advance the process, the idea itself is not commercialized because it does not contain a value proposition for any outside entity to take hold of. It is imperative to identify a product-market fit for an innovation as not all concepts should become companies and not all ideas impact the market. A strong technology translation capability cannot make up for an opportunity without a direct connection to an existing customer pain-point, which is only identified through a process of customer discovery outside of the university's walls.

Lastly, from a practical perspective, I would recommend that as part of the engagement with a larger set of academic entrepreneurs on campus (both successful and unsuccessful), the survey/interview deployed by the authors engage these individuals in soliciting programs, opportunities, efforts, and ideas to improve the existing stagnant innovation culture on campus. I believe by engaging these "customers" on campus in dialogue focused on solving the challenge, administrative support will be more easily achieved.

In conclusion, I believe the authors are on the right track and that their efforts have significant merit. I would urge them to continue their work, expand the sample size, examine a bit broader set of reasons why the problems exist and work with their respondents to improve the situation.

Competing Interests: No competing interests were disclosed.

\section{I confirm that I have read this submission and believe that I have an appropriate level of expertise to confirm that it is of an acceptable scientific standard, however I have significant reservations, as outlined above.}

Author Response 04 Aug 2015

Nathan Vanderford, University of Kentucky, Lexington, USA

Dear Dr. Facher,

Thank you for your time and comments. Your critique has helped guide us through revising the article. We would like to directly respond to some of your comments. We would first like to clarify that this case study was designed and conducted as a supplement to the prior study looking at the barriers associated with cancer research commercialization at the University of Kentucky (we have made this clarification in the new version of the article). The 
prior study's conclusions were based solely on the responses to the survey as individual interviews were not conducted. Thus, the intent of the current study was to collect more specific, supplemental information through interviews with "successful" entrepreneurs. Given this intent and the study's supplemental nature, we have purposefully not incorporated new research questions into the current case study. We have, however, at your suggestion, expanded the sample size by two respondents and this generated a number of additional significant comments that are important to understand regarding the university's low commercialization rate. We agree with your assertions that additional reasons for low commercialization activity likely exist and that expanding our research questions and sample size to include a mix of stakeholders involved in the research commercialization process (including faculty that have been unsuccessful at commercializing their research and staff/administrators of the commercialization process, etc.) would aid in uncovering other issues. We would like to note, however, that expansion of this current work would change the intent (described above) and design of our study. Therefore, we have maintained the overall intent and design of the study other than adding the additional respondents. We believe that this design will allow us to bring some additional closure to the prior study. Lastly, to offset additional concerns, we have included a description of the limitations of this case study in the methods sections.

In closing, we hope that you will review this revised version of the article in light of our changes based on your comments as well as those of the other two reviewers (we hope that you will read the other reviewers' comments as well as our response to those reviews) and in relation to its intended purpose of being a supplemental component to the prior study at the University of Kentucky.

Sincerely,

Nathan L. Vanderford and Elizabeth Marcinkowski

Competing Interests: No competing interests were disclosed.

Reviewer Report 17 June 2015

https://doi.org/10.5256/f1000research.6961.r9005

(c) 2015 Crick S. This is an open access peer review report distributed under the terms of the Creative Commons Attribution License, which permits unrestricted use, distribution, and reproduction in any medium, provided the original work is properly cited.

\section{Scott Crick}

Licensing Associate, Office of Technology Management, Washington University, St Louis, MO, USA

This study attempted to identify potential impediments to commercialization of research at the University of Kentucky. The authors point out that, according to data from AUTM, the University of Kentucky ranks near the bottom in a number of key metrics of commercialization when compared to its benchmark institutions. The goal of the study was to identify barriers to commercialization. 
These findings will then be brought to administration in hopes of rectifying the problem.

I think there are several issues with this work that, if addressed properly, will greatly strengthen its impact and utility not only at UK but also at other university technology transfer organizations.

The first issue I have with the work is the inclusion of only a single faculty member with entrepreneurial experience. The rationale given was that that person could provide more insight into the process as a whole. Looking at the data referenced in Table 1, the most striking discrepancy between UK and benchmark institutions is the number of invention disclosures. When the data are normalized to the number of invention disclosures per institution, UK appears to be making good use of the inventions that are disclosed to them. It seems to me that one of the major issues at UK is simply getting inventors. While I agree that the entrepreneurial faculty member could have a lot of insight into issues after the first step, I wonder how much insight this person provided with regards to why people are not disclosing inventions. I am certain it would be possible to identify faculty that publicly disclosed potentially valuable assets without ever filing an invention disclosure, and I would suggest understanding those issues are 1) extremely important for improving commercialization at UK, and 2) more easily addressable at an institutional level than some other potential barriers.

The second issue with relying on input from a single faculty member is that barriers are variable (as even mentioned in the article) not only between individuals, but between disciplines and subdisciplines as well. Although the individual faculty member can identify barriers he/she has experienced, it would be disingenuous to suggest these barriers and the relative weight given to each of them is an accurate reflection of the system as a whole. A minor point.....It would also be very helpful to know general field of research of the faculty member interviewed. "Translational" is very broad. Is he/she in pharma, biotech, medical devices, engineering...?

I have two recommendations to strengthen this article.

My first recommendation is that the authors include in the case study at least two other faculty members with technology commercialization experience (not necessarily on par with the initial interviewee). I would also suggest that these faculty be from distinct research areas and departments. Although still qualitative, it would be insightful to see if these people with different types of technology, different department makeup, and very likely different experiences and backgrounds still identify the same barriers.

My second recommendation is to limit the scope to barriers that are perceived after invention disclosure. It appears as though there is an issue at UK (which I should say is certainly not unique) that I suspect has to do with education of potential inventors such that a number of these people are not even considering that their technology might have commercialization potential. A followup study trying to tease apart this issue would be interesting and may have broader appeal.

Competing Interests: No competing interests were disclosed.

I confirm that I have read this submission and believe that I have an appropriate level of expertise to confirm that it is of an acceptable scientific standard, however I have significant reservations, as outlined above. 
Author Response 04 Aug 2015

Nathan Vanderford, University of Kentucky, Lexington, USA

Dear Dr. Crick,

We thank you for taking the time to review our case study. Your critique has helped shape our current version of the article. We would like to respond to some of your comments. First, per your suggestion, we have expanded our sample size by two respondents. This expansion lead to the collection of a significant amount of additional crucial comments that are important to understand about the issues related to the low commercialization activity at the University of Kentucky. Second, in regard to your question about the respondents' field of research, we understand your desire to have more information regarding the respondents' research areas, but we feel that for confidentiality purposes, we cannot be any more specific; given the small sample size of "successful" academic entrepreneurs at the University of Kentucky, reporting a respondent's specific research field could potentially allow for the identification of the subject. Next, you made very insightful comments regarding the desire to better understand the issues involved in the university's low invention disclosure rate. We agree with your points and we would also like to address this issue. With that said, however, we would like to clarify that this case study was designed and conducted as a supplement to the prior study looking at the barriers associated with cancer research commercialization at the University of Kentucky; the sole intent of the current study was to collect more specific, supplemental information through interviews with the respondents (we have now explicitly stated this intent in the new version of the article). Given this intent and the study's supplemental nature, we have purposefully not incorporated new research questions into the current case study. We feel that expanding the current study would likely change its primary intent. We do hope to address additional research questions, including understanding issues related to the low disclosure rate, in future work. Lastly, to offset additional concerns, we have included a description of the limitations of this case study in the methods sections.

In closing, we hope that you will review this revised version of the article in light of our changes based on your comments as well as those of the other two reviewers (we hope that you will read the other reviewers' comments as well as our response to those reviews) and in relation to its intended purpose of being a supplemental component to the prior study at the University of Kentucky.

Sincerely,

Nathan L. Vanderford and Elizabeth Marcinkowski

Competing Interests: No competing interests were disclosed.

Reviewer Report 05 June 2015

https://doi.org/10.5256/f1000research.6961.r8827 
(C) 2015 Silvaggi J. This is an open access peer review report distributed under the terms of the Creative Commons Attribution License, which permits unrestricted use, distribution, and reproduction in any medium, provided the original work is properly cited.

\section{Jessica Silvaggi \\ UWM Research Foundation, Milwaukee, WI, USA}

The goal of the authors was to document any impediments to the commercialization process at the University of Kentucky. The study was spurred by the findings that UK significantly underperforms when compared to peer institutions of similar size. A previous study was published in 2013 regarding this same topic at UK for the commercialization of cancer research. In this study, similar surveys were conducted with one single entrepreneurial respondent as opposed to a larger cohort of cancer researchers in the previous UK study.

They report that the major issue impeding commercialization, according to the respondent, is the lack of appropriate infrastructure at the university. The results were apparently similar to those found in this 2013 paper. I found this topic to be of great interest in comparing the performance to schools of similar benchmarks. The results could be helpful to many institutions that are underperforming and looking to boost commercialization. The survey questions used could be useful for any institution to keep track of the satisfaction of the researchers in regard to commercialization of their technologies, and to assess the adequacy of the performance of the technology transfer office.

\section{Major concerns/Revisions}

1. While I think the survey questions used were reasonable, I have doubts about the validity of asking a single entrepreneur the survey questions. It comes across as if the same 2013 study was repeated, but with only one person. I don't feel that one person is a significant number for this type of paper to make conclusions with. $\mathrm{N}=1$ doesn't seem to be a true scientific sampling. Unfortunately, if more respondents were utilized, then this paper would appear to be a repeat of the earlier study. Perhaps another angle would be to survey the staff at UK as to why they are underperforming. Asking the tech transfer professionals and other research administrators would also be informative and provide a different angle to the original survey of cancer researchers. Or perhaps a broader survey of other departments would be helpful, rather than only focusing on the cancer department.

2. I feel that several other angles could have also been explored in this paper to contrast or follow up on the work in the 2013 paper about UK. After the first study were any changes made based on the conclusions? Did the number of staff change? Did any of the infrastructure change at UK? Did UK do anything to increase the level of commercialization? There are many other interesting questions that could be explored rather than repeating the study over again with one participant.

3. If the university has not responded to the previous study in any fashion, I find that of great interest. Why hasn't the technology transfer office been expanded and further supported? Why is there no incentive by those in charge of this area to revamp the office? There has been a large push at many universities to further promote entrepreneurship in faculty and students and support commercialization. In some online information it states that in the 
past UK was pushing to be a top 20 university by 2020. I am curious to know why there has been no change in the recent years.

Minor Revisions

1. When comparing benchmarks, another important factor missing in the table is the amount of research dollars. There is a ratio of expected disclosures per millions of dollars of research which varies, but is quoted in several locations at 1 disclosure per $\$ 1.5 \mathrm{M}-\$ 3 \mathrm{M}$ and 1 start-up company per $\sim \$ 100 \mathrm{M}$. Knowing the amount of research dollars going into UK would help to show a lack of productivity with inventions at the university. This information should be available through AUTM if not through the technology transfer office directly. Based on some online information the research expenditures at UK appear to be in the hundreds of millions of dollars. Assuming $\sim \$ 400 \mathrm{M}$ in expenditures, one would expect about 130 disclosures. The UK website cites 84 disclosures in 2014.

\section{Summary:}

I feel that major revisions are necessary for this paper to add some new information and expand the scope of the study. The results here do not seem to add onto those previously found but simply confirm the previous findings with the survey of one entrepreneurial researcher. A different sample of respondents would greatly enhance this paper such as asking researchers from all departments, or focusing on the staff involved in technology transfer, commercialization and entrepreneurship. Or perhaps if changes were made by the tech transfer office and these did not have an effect, this would be good to know for other offices. There appears to be something missing from this story. This paper would be of interest if revamped to add a new twist distinct from the 2013 paper.

I have read this submission. I believe that I have an appropriate level of expertise to confirm that it is of an acceptable scientific standard.

Competing Interests: No competing interests were disclosed.

\section{I confirm that I have read this submission and believe that I have an appropriate level of expertise to confirm that it is of an acceptable scientific standard, however I have significant reservations, as outlined above.}

Author Response 04 Aug 2015

Nathan Vanderford, University of Kentucky, Lexington, USA

Dear Dr. Silvaggi,

We greatly appreciate the time you dedicated to review our article. We found your comments very helpful as we revised the article. We are happy that you found this topic of interest and applicable to other institutions. Before reading the new version, we would like to address some of your comments and concerns. First, we appreciate your concerns regarding the "n-of-1" design of the study. As suggested by each reviewer, we have added two additional respondents to the study and this did indeed generate several additional important points regarding the issues related to the low commercialization activity at the University of Kentucky. Second, we appreciate your comments regarding how this work 
could be construed as a repeat of the prior study. We agree with your assertions that other issues are likely involved in the low commercialization activity at the university and we agree that surveying a mix of stakeholders involved in the research commercialization process could aid in uncovering other issues. However, we would like to clarify that this case study was, in fact, specifically designed and conducted as a supplement to the prior work looking at the barriers associated with cancer research commercialization at the University of Kentucky (we have made this clarification in the new version of the article). The prior study's conclusions were based solely on the responses to the survey and individual interviews were not conducted. The intent of the current study was to collect more specific, supplemental information through interviews. Given this intent and the study's supplemental nature, we have purposefully not incorporated new research questions into the current case study. We believe that future work would best address many of your comments which add additional research questions that would help understand other issues that may be connected to the low research commercialization activity. You have also made several important comments regarding whether the university has made any changes in the research commercialization process since the 2013 study. In fact, few changes have been made and that is one reason why it was important to conduct this case study; it was important to obtain specific comments from "successful" entrepreneurs so that these individuals could identify specific issues in the system. Finally, to offset additional concerns, we have included a description of the limitations of this case study in the methods sections. Per your minor point, we have now also added research expenditures to Table 1.

In closing, we hope that you will review this revised version of the article in light of our changes based on your comments as well as those of the other two reviewers (we hope that you will read the other reviewers' comments as well as our response to those reviews) and in relation to its intended purpose of being a supplemental component to the prior study at the University of Kentucky.

Sincerely,

Nathan L. Vanderford and Elizabeth Marcinkowski

Competing Interests: No competing interests were disclosed. 
The benefits of publishing with F1000Research:

- Your article is published within days, with no editorial bias

- You can publish traditional articles, null/negative results, case reports, data notes and more

- The peer review process is transparent and collaborative

- Your article is indexed in PubMed after passing peer review

- Dedicated customer support at every stage

For pre-submission enquiries, contact research@f1000.com 